V. I. LOMOVOY, master, National University "Odessa Maritime Academy", Odessa,

V. D. PAVLENKO, Doct. Sci, Prof., Odessa National Polytechnical University, Odessa

\title{
IDENTIFICATION NONLINEAR DYNAMIC SYSTEMS BASED ON VOLTERRA POLYNOMIALS WITH USING POLYHARMONIC TEST SIGNALS
}

The method is proposed for constructing the Volterra approximation model of the nonlinear dynamical systems in the frequency domain using of the test polyharmonic signals of various amplitudes. The computational identification method is based on the use of the regularized least squares method and the choice of the optimal step size on amplitude of test signals. The accuracy and computational stability of identification method in the form of multidimensional amplitude-frequency and phase-frequency characteristics are investigated. The method improves an accuracy and stability of the identification procedure. Figs.: 2. Refs.: 18 titles.

Keywords: nonlinear dynamic systems; Volterra approximation model; phasefrequency characteristics; polyharmonic test signals; regularized least squares method.

Introduction. Methods of mathematical modeling and experiment are the main tools for research of complex nonlinear dynamic systems (NDS) [1]. For the description of NDS, which are considered as a "black box", integropower series are often used - Volterra models [2 - 6]. In this case, the nonlinear and dynamic properties of the system are completely characterized by a sequence of multidimensional weight functions - Volterra kernels.

Commonly, the Volterra series are replaced by a polynomial, with only taking several first terms of series into consideration. Nonlinear dynamical system identification in a form of Volterra series consists in the determination of $n$-dimensional weighting functions $w_{n}\left(\tau_{1}, \ldots, \tau_{n}\right)$ in time domain $[6,7]$ or it's Fourier transforms $W_{n}\left(j \omega_{1}, \ldots, j \omega_{n}\right)-n$-dimensional transfer functions in frequency domain $[6,8-13]$ on the input-output data of the NDS.

The scope of models in the form of integro-power series is limited to a weakly non-linear mode of operation, that is, the work of the NDS at small amplitudes of input signals or small non-linearity. To describe a substantially nonlinear system, Volterra integro-power polynomials are used. The theorem proved by M. Frechet justifies the possibility of such an approximation. However, the theorem does not give constructive algorithms for constructing Volterra polynomials from the input-output data [14].

The aim of this work is a theoretical substantiation and research of the

(C) Lomovoy V.I., Pavlenko V.D., 2019 
method of constructing the approximation model of the NDS in the form of the Volterra polynomials in frequency domain with using the test polyharmonic signals.

Identification of nonlinear system in frequency domain consists in determination of absolute value and phase of multidimensional transfer function at given frequencies - multidimensional amplitude-frequency (AFC) $\left|W_{n}\left(j \omega_{1}, \ldots, j \omega_{n}\right)\right|$ and phase-frequency characteristics (PFC) $\arg W_{n}\left(j \omega_{1}, \ldots, j \omega_{n}\right)$, which are defined by formulas:

$$
\begin{gathered}
\left|W_{n}\left(j \omega_{1}, \ldots, j \omega_{n}\right)\right|=\sqrt{\left[\operatorname{Re}\left(W_{n}\left(j \omega_{1}, \ldots, j \omega_{n}\right)\right)\right]^{2}+\left[\operatorname{Im}\left(W_{n}\left(j \omega_{1}, \ldots, j \omega_{n}\right)\right)\right]^{2}}, \\
\arg W_{n}\left(j \omega_{1}, \ldots, j \omega_{n}\right)=\operatorname{arctg} \frac{\operatorname{Im}\left[W_{n}\left(j \omega_{1}, \ldots, j \omega_{n}\right)\right]}{\operatorname{Re}\left[W_{n}\left(j \omega_{1}, \ldots, j \omega_{n}\right)\right]},
\end{gathered}
$$

where Re and Im - accordingly real and imaginary parts of a complex function of $n$ variables respectively.

The method of identification the Volterra approximation model. A method of constructing approximation Volterra model of the nonlinear dynamical systems (NDS) is developing [14]. Method of the identification is based on the approximation of the response $y(t)$ system at an arbitrary deterministic signal $x(t)$ in the form of integral power of the polynomial Volterra $N$-th order ( $N$-order approximation model):

$$
\tilde{y}_{N}(t)=\sum_{n=1}^{N} \hat{y}_{n}(t)=\sum_{n=1}^{N} \int_{0}^{\infty} \ldots \int_{\text {times }}^{\infty} w_{0}^{\infty} w_{n}\left(\tau_{1}, \ldots, \tau_{n}\right) \prod_{i=1}^{n} x\left(t-\tau_{i}\right) d \tau_{i} .
$$

The statement which proof is given in [14] is true.

Statement 1. Let the input test signals NDS are fed alternately $a_{1} x(t)$, $a_{2} x(t), \ldots, a_{L} x(t) ; a_{1}, a_{2}, \ldots, a_{L}$ - distinct real numbers satisfying the condition $\left|a_{j}\right| \leq 1$ for $\forall j=1,2, \ldots, L$; then

$$
\begin{gathered}
\tilde{y}_{N}\left[a_{j} x(t)\right]=\sum_{n=1}^{N} \hat{y}_{n}\left[a_{j} x(t)\right]= \\
=\sum_{n=1}^{N} a_{j}^{n} \int_{0}^{\infty} \ldots \int_{\text {times }}^{0} w_{n}\left(\tau_{1}, \ldots, \tau_{n}\right) \prod_{i=1}^{n} x\left(t-\tau_{i}\right) d \tau_{i}=\sum_{n=1}^{N} a_{j}^{n} \hat{y}_{n}(t) .
\end{gathered}
$$

The partial components in the approximation model $\hat{y}_{n}(t)$ are found using the least square method. This makes it possible to obtain such evaluation in which the sum of squared deviations of responses identified the nonlinear 
dynamical system $y\left[a_{j} x(t)\right]$ on the model $\hat{y}_{N}\left[a_{j} x(t)\right]$ response is minimal, i.e., NDS provides a minimum criterion

$$
J_{N}=\sum_{j=1}^{L}\left(y\left[a_{j} x(t)\right]-\widetilde{y}_{N}\left[a_{j} x(t)\right]\right)^{2}=\sum_{j=1}^{L}\left(y_{j}(t)-\sum_{n=1}^{N} a_{j}^{n} \hat{y}_{n}(t)\right)^{2} \rightarrow \min ,
$$

where $y_{j}(t)=y\left[a_{j} x(t)\right]$. Minimization of the criterion (5) is reduced to solving the system of normal equations of Gauss, which in vector-matrix form can be written as

$$
A^{\prime} A \hat{y}=A^{\prime} \bar{y} \text {, }
$$

where $\mathrm{A}^{\prime}$ - transposed matrix,

$$
\mathrm{A}=\left[\begin{array}{cccc}
a_{1} & a_{1}^{2} & \cdots & a_{1}^{N} \\
a_{2} & a_{2}^{2} & \cdots & a_{2}^{N} \\
\cdots & \cdots & \cdots & \cdots \\
a_{L} & a_{L}^{2} & \cdots & a_{L}^{N}
\end{array}\right], \quad \overline{\mathrm{y}}=\left[\begin{array}{c}
y_{1}(t) \\
y_{2}(t) \\
\cdots \\
y_{L}(t)
\end{array}\right], \quad \hat{\mathrm{y}}=\left[\begin{array}{c}
\hat{y}_{1}(t) \\
\hat{y}_{2}(t) \\
\cdots \\
\hat{y}_{N}(t)
\end{array}\right] .
$$

From (6) we obtain

$$
\hat{y}=\left(A^{\prime} A\right)^{-1} A^{\prime} \bar{y} .
$$

In (7), matrix operations, we obtain

$$
\left[\begin{array}{c}
\hat{y}_{1}(t) \\
\hat{y}_{2}(t) \\
\cdots \\
\hat{y}_{N}(t)
\end{array}\right]=\left[\begin{array}{cccc}
\sum_{j=1}^{L} a_{j}^{2} & \sum_{j=1}^{L} a_{j}^{3} & \cdots & \sum_{j=1}^{L} a_{j}^{N+1} \\
\sum_{j=1}^{L} a_{j}^{3} & \sum_{j=1}^{L} a_{j}^{4} & \cdots & \sum_{j=1}^{L} a_{j}^{N+2} \\
\cdots & \cdots & \cdots & \cdots \\
\sum_{j=1}^{L} a_{j}^{N+1} & \sum_{j=1}^{L} a_{j}^{N+2} & \cdots & \sum_{j=1}^{L} a_{j}^{2 N}
\end{array}\right]^{-1} \cdot\left[\begin{array}{c}
\sum_{j=1}^{L} a_{j} y_{j}(t) \\
\sum_{j=1}^{L} a_{j}^{2} y_{j}(t) \\
\cdots \\
\sum_{j=1}^{L} a_{j}^{N} y_{j}(t)
\end{array}\right] .
$$

The Tikhonov regularization method based on the variational method of constructing a regularizing operator is used to obtain the error-resistant to solving a system of linear algebraic equations (SLAE) (6) [15]. This method is to determine an approximative solution vector that minimizes a certain smooth functionality. The only vector satisfying the minimum condition of the smoothing functional is determined on the basis of the SLAE solution

$$
\left(\mathrm{A}^{\prime} \mathrm{A}+\alpha \mathrm{I}\right) \hat{\mathrm{y}}_{\alpha}=\mathrm{A}^{\prime} \overline{\mathrm{y}} \text {, }
$$


where $\mathrm{I}-$ the unit matrix, and $\alpha$ is a parameter of regularization.

When implementing this algorithm, the regularization parameter $\alpha$ is chosen quite small (from the analysis of the available information about the error of the input data and the error of calculations). The value of the regularization parameter $\alpha$ is determined by matching, that is, multiple calculations $\hat{\mathrm{y}}_{\alpha}$, for different values $\alpha$.

Using test polyharmonic signals in identification procedure. For identification in the frequency domain the test polyharmonic signals are used. We prove:

Statement 2. If test polyharmonic signal is used in form

$$
x(t)=A \sum_{k=1}^{n} \cos \left(\omega_{k} t\right)=\frac{A}{2} \sum_{k=1}^{n}\left(e^{j \omega_{k} t}+e^{-j \omega_{k} t}\right),
$$

then the $n$-th partial component of the response of test system can be written in the form:

$$
\begin{aligned}
& y_{n}(t)=\frac{A^{n}}{2^{n-1}} \sum_{m=0}^{\mathrm{E}(n / 2)} C_{n}^{m} \sum_{k_{1}=1}^{n} \ldots \sum_{k_{n}=1}^{n}\left|W_{n}\left(-j \omega_{k_{1}}, \ldots,-j \omega_{k_{m}}, j \omega_{k_{m+1}}, \ldots, j \omega_{k_{n}}\right)\right| \times \\
& \times \cos \left(\left(-\sum_{l=0}^{m} \omega_{k_{l}}+\sum_{l=m+1}^{n} \omega_{k_{l}}\right) t+\arg W_{n}\left(-j \omega_{k_{1}}, \ldots,-j \omega_{k_{m}}, j \omega_{k_{m+1}}, \ldots, j \omega_{k_{n}}\right)\right),
\end{aligned}
$$

where $\mathrm{E}()$ - function used to obtain the of integer part of the value [11].

The partial components for $n=1,2$ and 3 are the form, respectively

$$
\begin{gathered}
y_{1}(t)=A\left|W_{1}(j \omega)\right| \cos \left(\omega t+\arg W_{1}(j \omega)\right), \\
y_{2}(t)=\frac{A^{2}}{2} \sum_{k_{1}, k_{2}=1}^{2}\left|W_{2}\left(j \omega_{k_{1}}, j \omega_{k_{2}}\right)\right| \cos \left(\left(\omega_{k_{1}}+\omega_{k_{2}}\right) t+\right. \\
\left.+\arg W_{2}\left(j \omega_{k_{1}}, \omega_{k_{2}}\right)\right)+ \\
+A^{2} \sum_{k_{1}, k_{2}=1}^{2}\left|W_{2}\left(-j \omega_{k_{1}}, j \omega_{k_{2}}\right)\right| \cos \left(\left(-\omega_{k_{1}}+\omega_{k_{2}}\right) t+\right. \\
\left.+\arg W_{2}\left(-j \omega_{k_{1}}, \omega_{k_{2}}\right)\right)
\end{gathered}
$$




$$
\begin{gathered}
y_{3}(t)=\frac{A^{3}}{4} \sum_{k_{1}, k_{2}, k_{3}=1}^{3}\left|W_{3}\left(j \omega_{k_{1}}, j \omega_{k_{2}}, j \omega_{k_{3}}\right)\right| \cos \left(\left(\omega_{k_{1}}+\omega_{k_{2}}+\omega_{k_{3}}\right) t+\right. \\
\left.+\arg W_{3}\left(j \omega_{k_{1}}, j \omega_{k_{2}}, j \omega_{k_{3}}\right)\right)+ \\
+\frac{3 A^{3}}{4} \sum_{k_{1}, k_{2}, k_{3}=1}^{3}\left|W_{3}\left(-j \omega_{k_{1}}, j \omega_{k_{2}}, j \omega_{k_{3}}\right)\right| \cos \left(\left(-\omega_{k_{1}}+\omega_{k_{2}}+\omega_{k_{3}}\right) t+\right. \\
\left.+\arg W_{3}\left(-j \omega_{k_{1}}, j \omega_{k_{2}}, j \omega_{k_{3}}\right)\right)+ \\
+\frac{3 A^{3}}{4} \sum_{k_{1}, k_{2}, k_{3}=1}^{3}\left|W_{3}\left(-j \omega_{k_{1}},-j \omega_{k_{2}}, j \omega_{k_{3}}\right)\right| \cos \left(\left(-\omega_{k_{1}}-\omega_{k_{2}}+\omega_{k_{3}}\right) t+\right. \\
\left.+\arg W_{3}\left(-j \omega_{k_{1}},-j \omega_{k_{2}}, j \omega_{k_{3}}\right)\right) .
\end{gathered}
$$

The component with frequency $\omega_{1}+\ldots+\omega_{n}$ is extracted from the response to test signal (10)

$$
A^{n}\left|W_{n}\left(j \omega_{1}, \ldots, j \omega_{n}\right)\right| \cos \left[\left(\omega_{1}+\ldots+\omega_{n}\right) t+\arg W_{n}\left(j \omega_{1}, \ldots, j \omega_{n}\right)\right] .
$$

Certain limitations should be imposed while choosing of frequences polyharmonic test signals in the process determine multidimensional AFC and PFC [11].

The technique and hardware-software tools of radio frequency communication channel identification. Experimental research of an Ultra High Frequency range communication channel (CC) for the purpose of identification of its multifrequency performances, characterizing nonlinear and dynamic properties of the channel are fulfilled $[16,17]$. The Volterra model in the form of the second order polynomial is used. Thus physical channel properties are characterized by transfer functions of $W_{1}(j \omega)$ and $W_{2}\left(j \omega_{1}, j \omega_{2}\right)-$ by the Fourier-images of weighting functions $w_{1}(t)$ and $6 w_{2}\left(t_{1}, t_{2}\right)$.

Implementation of identification method on the IBM PC computer basis has been carried out using the developed software in $\mathrm{C}++$ language with the usage of such classes as CWaveRecorder, CWavePlayer, CWaveReader, CWaveWriter which allow to provide rather convenient interacting with MMAPI Windows. The software allows automating the process of the test signals forming with the given parameters (amplitudes and frequencies). Also this software allows transmitting and receiving signals through an output and input section of computer soundcard, to produce segmentation of a file with the responses to the fragments, corresponding to the communication channel responses being researched on test polyharmonic effects with different amplitudes. 
In experimental research two identical S.P.RADIO A/S, T\&T VHF-radio stations (a range of operational frequencies 146-174 MHz) and IBM PC with Creative SBLive! sound cards were used. Sequentially AFC of the first and second orders were defined. The method of identification with an order of approximation $N=4$ was applied. Structure charts of identification procedure - determinations of the $n$-order AFC of CC are presented accordingly on figure 1. The general scheme of a hardware-software complex of the communication channel identification, based on the data of input-output type experiment is presented in fig. 1 .

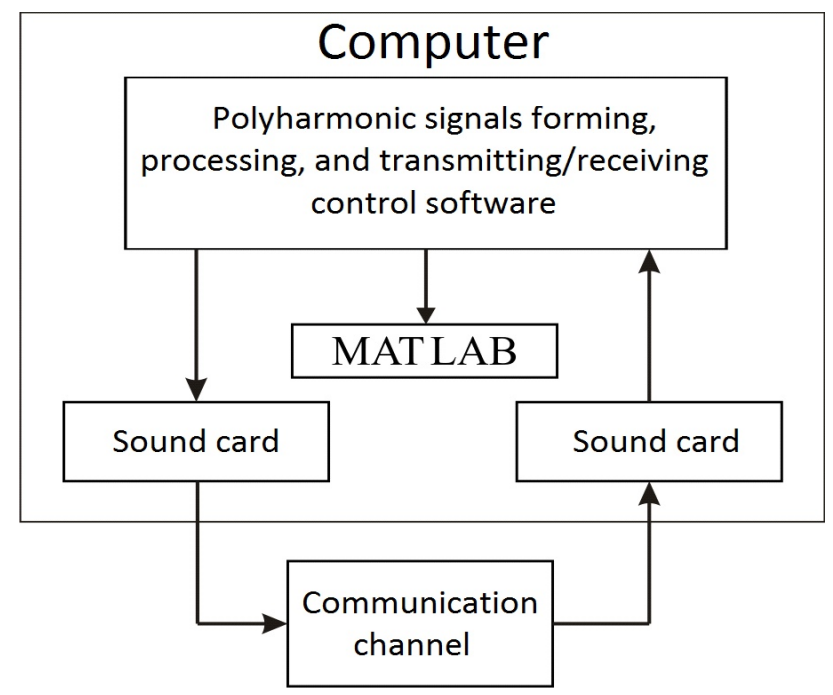

Fig. 1. The general scheme of the experiment

The communication channel received responses to the test signals, compose a group of the signals, which amount is equal to the used order of approximation $N(N=4)$. In each following group the signals frequency increases by magnitude of chosen step. To define the beginning of each received response we have used a cross-correlation.

Maximum allowed amplitude in described experiment with use of sound card was $0,2 \mathrm{~V}$ (defined experimentally). The used range of frequencies was defined by the sound card pass band, and frequencies of the test signals has been chosen from this range, taking into account restrictions specified above. Such parameters were chose for the experiment: start frequency $-200 \mathrm{~Hz}$; final frequency $-1600 \mathrm{~Hz}$; a frequency change step $-27 \mathrm{~Hz}$; to define AFC of the second order determination, an offset on frequency $\omega_{2}-\omega_{1}$ was equal 25 , 50 and $100 \mathrm{~Hz}$. 
The weighed sum is formed from received signals-responses of each group. As a result we get partial components of response of the communication channel $y_{1}(t)$ and $y_{2}(t)$. For each partial component of response a Fourier transform (the FFT is used) is calculated, and from received spectra only an informative harmonics (which amplitudes represents values of required characteristics of the first and second orders AFC) are taken. The first order $\mathrm{AFC}\left|W_{1}(j \omega)\right|$ is received by extracting the harmonics with frequency $\omega$ from the spectrum of the partial response of the CC $y_{1}(t)$. The second order AFC $\left|W_{2}\left(j \omega_{1}, j \omega_{2}\right)\right|$ we received extracting the harmonics with summary frequency $\omega_{1}+\omega_{2}$ from the spectrum of the partial response of the communication channel $y_{2}(t)$ to the test signal A $\cdot \cos \left(\omega_{1} \cdot t\right)+A \cdot \cos \left(\omega_{2} \cdot t\right)$.

The results are received after digital data processing of the experiments for the first and second orders. AFC $\left|W_{1}(j \omega)\right|$ and $\left|W_{2}\left(j \omega_{1}, j \omega_{2}\right)\right|$ after procedure of smoothing based on the wavelet transform [18] are presented in fig. 2 .

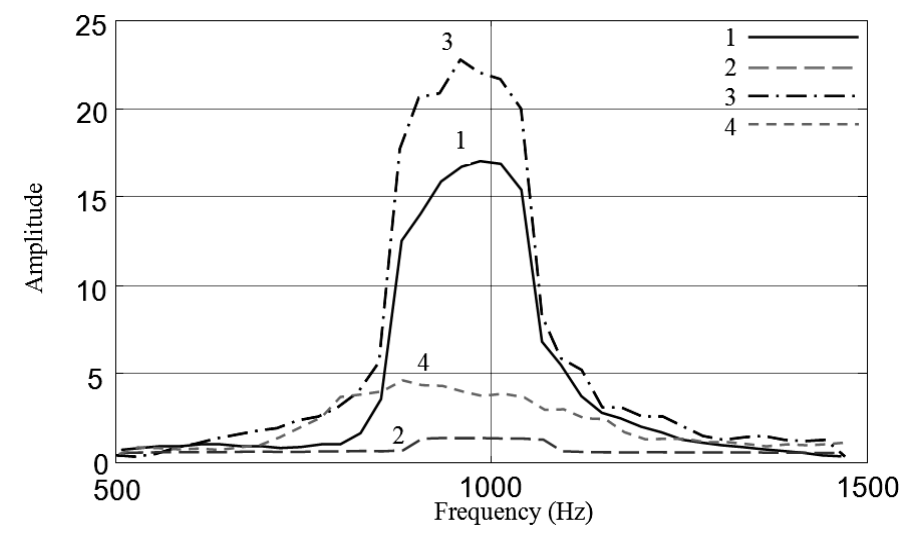

Fig. 2. AFC of the first order after smoothing -1 , the second order AFC after smoothing at: $\Delta \Omega=25 \mathrm{~Hz}-2 ; \Delta \Omega=50 \mathrm{~Hz}-3 ; \Delta \Omega=100 \mathrm{~Hz}-4$

Conclusion. The method for building the Volterra approximation model of the nonlinear dynamical system with using of the test polyharmonic signals of various amplitudes is proposed. The computing identification method is based on the use of the regularized least squares method. The accuracy and computational stability of identification method in the form of multidimensional amplitude-frequency and phase-frequency characteristics are investigated. The method improves an accuracy and stability of the identification procedure.

The results of the identification of the NDS based on the approximation model in the form of a Volterra polynomial using test polyharmonic signals are significantly affected by measurement errors. The computational algorithm 
that implements such method of identification is reduced to solving a system of linear algebraic equations (SLAE) for each fixed point in time $t$ on the simulation interval. The method of regularization of ill-posed Tikhonov problems, based on the variational method of constructing a regularizing operator, is used to obtain the solutions of the SLAE, that are tolerant towards the measurement's errors. To improve the computational stability of the identification method, a noise reduction (smoothing) procedure was applied to the obtained estimates of the characteristics of the AFC and PFC based on the wavelet transform.

The technique of experimental research of continuous communication channel of the telecommunication system is developed for the identification of its characteristics regarding to the nonlinear and dynamic properties on the basis of the Volterra models in the frequency domain. The technique is based on application of the approximating model for identification of the nonlinear dynamic system using to the input polyharmonic signals of different amplitudes.

The hardware-software tools are developed implementing the technique of identification and they are applied to create an information model of the communication channel in the form of the first and second orders AFC on the basis of the data of input-output type experiment with the usage of the test harmonic and biharmonic signals.

The received results of research show essential nonlinearity of the communication channel that leads to distortions of the signals in a radio section, reduces an important parameters of the telecommunication system: accuracy of the reproduction signals, channel bandwidth, noise immunity.

\section{Referenses:}

1. Giannakis, G.B. (2001), "A bibliography on nonlinear system identification and its applications in signal processing, communications and biomedical engineering", Signal Processing - EURASIP, Elsevier Science B.V., vol. 81, No. 3, pp. 533-580.

2. Doyle, F.J., Pearson, R.K., and Ogunnaike, B.A. (2001), Identification and Control Using Volterra Models, Published Springer Technology \& Industrial Arts, 314 p.

3. Pupkov, K.A., and Yegupov, N.D. (2004), Methods of classical and modern theory of automatic control. Statistical dynamics and identification of automatic control systems: Textbook for universities, T. 2, 2-th ed., Moskov, MGTU named by N.E. Bauman, 638 p.

4. Pupkov, K.A., Kapalin, V.I., and Yushchenko, A.S. (1976), Functional series in the theory of nonlinear systems, Moskov, Science, $448 \mathrm{p}$.

5. Popkov, Yu.S. Kiselev, O.N., Petrov, N.P., and Shmulian B.L. (1976), Identification and optimization of nonlinear stochastic systems, Moskov, Energy, $440 \mathrm{p}$.

6. Danilov, L.V., Matkhanov, L.N., and Filippov, V.S. (1990), Theory of Nonlinear Electrical Circuits, Leningrad, Energoatomizdat, 256 p.

7. Pavlenko, Vitaliy, and Pavlenko, Sergey (2018), "Deterministic Identification Methods for Nonlinear Dynamical Systems based on the Volterra Model", Applied Aspects of Information Technology, No. 01 (01), pp. 9-29. 
8. Cheng, C.M., Peng, Z.K., Zhang, W.M., and Meng, G. (2016), "Volterra-series-based nonlinear system modeling and its engineering applications: A state-of-the-art review", Mechanical Systems and Signal Processing, November, pp. 1-25.

9. Pavlenko, V., Pavlenko, S., and Speranskyy, V. (2014), "Identification of systems using Volterra model in time and frequency domain", In book: "Advanced Data Acquisition and Intelligent Data Processing". V. Haasz and K. Madani (Eds.). Chapter 10, River Publishers, pp. 233-270.

10. Lomovoy, Volodimir, and Pavlenko, Vitaliy (2019), "Methods and Tools for Identification of Nonlinear Dynamical Systems based on Volterra Models in Frequency Domain", Scientific notes of TNU Vernadsky. Series: Technical Sciences, vol. 30 (69), Part 1, No.1, pp. 78-96.

11. Pavlenko, V., Pavlenko, S., and Lomovoy V. (2018), "Computational tools for the construction of Volterra models of nonlinear dynamic systems in the frequency domain", Bulletin of NTU "KhPI". Special Issue: Informatics and Modeling, No. 42 (1318), pp. 48-63.

12. Pavlenko, V. Speranskyy, V., Ilyin, V., and Lomovoy, V. (2012), "Modified Approximation Method for Identification of Nonlinear Systems Using Volterra Models in Frequency Domain", Applied Mathematics in Electrical and Computer Engineering: Proc. of the AMERICAN-MATH '12 \& CSST '12 \& CEA'12, Harvard, Cambridge, USA, January 2527, Published by WSEAS Press, pp. 423-428.

13. Pavlenko, V.D., and Speranskyy, V.O. (2013), "Analysis of Identification Accuracy of Nonlinear System Based on Volterra Model in Frequency Domain", American Journal of Modeling and Optimization, No. 1 (2), pp. 11-18.

14. Pavlenko, V.D., and Lomovoy, V.I. (2018), "Construction of an approximation model of a nonlinear dynamical system in the form of a Volterra polynomial", Notes of the VI Taurida National University Vernadsky. Series: Technical Sciences, vol. 29 (68), No. 6, pp. 200-205.

15. Pavlenko, S.V., and Pavlenko, V.D. (2015), "Regularization of the procedure for identifying nonlinear systems in the form of Volterra models" [Electronic resource], System Identification and Management Tasks: Proceedings of the $\mathrm{X}$ International Conference SICPRO'15, Moscow, January 26-29, Inst. of problems of management. V.A. Trapeznikova RAS, Moscow, IPU RAS, pp. 230-238.

16. Pavlenko, V.D., Lomovoy, V.I. and Issa, S.I.M. (2010), "Identification of a continuous communication channel with regard to its nonlinear and inertial properties", East European Advanced Technology Journal, Kharkov, No. 6/8 (48), pp. 13-18.

17. Pavlenko, V.D., Lomovoy, V.I., Speranskyy, V.A., and Ilyin, V.M (2011), "Radio frequency test method for wireless communications using Volterra model, In book: Dynamical Systems. Nonlinear Dynamics and Control". Editors: J. Awrejcewicz, M. Kaźmierczak, P. Olejnik, J. Mrozowski, Publisher Łódź, Poland, pp. 446-452.

18. Pavlenko, S.V. (2010), Wavelet filtering in the identification of non-linear systems based on Volterra models, East European Advanced Technology Journal, Kharkov, No. 6/4 (48), pp. 65-70.

The article was presented by Dr. Tech. Sciences, prof. NTU "KhPI", A.A. Serkov.

Received 15.04.2019

Lomovoy Volodimir, master

National University "Odessa Maritime Academy"

Str. Didrihsone, 8, Odessa, Ukraine, 65029

tel./phone: (063) 157-86-83, e-mail:lomovoy_vi@ukr.net

ORCID ID: 0000-0003-0864-3839 
Вісник Національного технічного університету "ХПІ", 2019, № 13 (1338) ISSN 2079-0031 (Print) ISSN 2411-0558 (Online)

Pavlenko Vitaliy, Dr.Sci.Tech, Professor Odessa National Polytechnical University Ave. Shevchenko, 1, Odessa, Ukraine, 65044

tel./phone: (048) 705-84-36, e-mail: pavlenko_vitalij@ukr.net ORCID ID: 0000-0002-5655-4171 
УДК 681.5.015.52

Ідентифікація нелінійних динамічних систем на основі поліномів Вольтерра з використанням полігармонічних тестових сигналів / Ломовой В.І., Павленко В.Д. // Вісник НТУ "ХПІ". Серія: Інформатика та моделювання. - Харків: НТУ "ХПІ". - 2019. - № 13 (1338). - С. $74-84$.

Запропоновано метод побудови апроксимаційної моделі Вольтерра нелінійних динамічних систем у частотній області 3 використанням тестових полігармонічних сигналів різної амплітуди. Обчислювальний метод ідентифікації заснований на використанні методу регулярізованних найменших квадратів і виборі оптимальної величини кроку по амплітуді тестових сигналів. Досліджується точність та обчислювальна стійкості методу ідентифікації у вигляді багатовимірних амплітудно- та фазо-частотних характеристик. Метод підвищує точність і стабільність результатів ідентифікації. Іл.: 2. Бібліогр.: 18 назв.

Ключові слова: нелінійні динамічні системи; апроксимаційна модель Вольтерра; полігармонічні тестові сигнали; метод регулярізованих найменших квадратів.

\section{УДК 681.5.015.52}

Идентификация нелинейных динамических систем на основе полиномов Вольтерра с использованием полигармонических тестовых сигналов / Ломовой В.И., Павленко В.Д. // Вестник НТУ "ХПИ". Серия: Информатика и моделирование. - Харьков: НТУ "ХПИ". - 2019. - № 13 (1338). - С. 74 - 84.

Предложен метод построения аппроксимационной модели Вольтерра нелинейных динамических систем в частотной области с использованием тестовых полигармонических сигналов различной амплитуды. Вычислительный метод идентификации основан на использовании метода наименьших квадратов с регуляризацией и выборе оптимальной величины шага по амплитуде тестовых сигналов. Исследуется точность и вычислительная устойчивость метода идентификации в виде многомерных амплитудно- и фазо-частотных характеристик. Метод повышает точность и стабильность результатов идентификации. Ил.: 2. Библиогр.: 18 назв.

Ключевые слова: нелинейные динамические системы; аппроксимационная модель Вольтера; тестовые полигармонические сигналы; метод наименьших квадратов с регуляризацией.

\section{UDC 681.5.015.52}

Identification nonlinear dynamic systems based on Volterra polynomials with using polyharmonic test signals / Lomovoy V.I., Pavlenko V.D. // Herald of the National Technical University "KhPI". Series of "Informatics and Modeling". - Kharkov: NTU "KhPI". - 2019. - №.13 (1338). - P. 74 - 84.

The method is proposed for constructing the Volterra approximation model of the nonlinear dynamical systems in the frequency domain using of the test polyharmonic signals of various amplitudes. The computational identification method is based on the use of the regularized least squares method and the choice of the optimal step size on amplitude of test signals. The accuracy and computational stability of identification method in the form of multidimensional amplitude-frequency and phase-frequency characteristics are investigated. The method improves an accuracy and stability of the identification procedure. Figs.: 2. Refs.: 18 titles.

Keywords: nonlinear dynamic systems; Volterra approximation model; polyharmonic test signals; phase-frequency characteristics; regularized least squares method. 